\title{
Combination of Genetic Aberration With International Staging System Classification for Stratification of Asian Multiple Myeloma Patients Undergoing Autologous Stem Cell Transplantation
}

\author{
JA MIN BYUN ${ }^{1,2}$, DAEYOON KIM ${ }^{3}$, DONG-YEOP SHIN ${ }^{2}$, INHO KIM ${ }^{2}$, \\ YOUNGIL $\mathrm{KOH}^{2}$ and SUNG-SOO YOON ${ }^{2,3}$ \\ ${ }^{1}$ Department of Internal Medicine, Seoul Metropolitan Government Seoul National \\ University Boramae Medical Center, Seoul, Republic of Korea; \\ ${ }^{2}$ Department of Internal Medicine, Seoul National University College of Medicine, \\ Seoul National University Hospital, Seoul, Republic of Korea; \\ ${ }^{3}$ Cancer Research Institute, Seoul National University Hospital, Seoul, Republic of Korea
}

\begin{abstract}
Background/Aim: The aim of the study was to contribute to the development of adaptive risk stratification methods specific to Asian multiple myeloma (MM) patients undergoing autologous stem cell transplantation (ASCT). Patients and Methods: We conducted this study to evaluate the prognostic impact of genetic abnormalities detected by fluorescent in situ hybridization (FISH) on survival outcomes in combination with the International Staging System (ISS) classification in 161 MM patients. This was a single-center retrospective longitudinal cohort study of newly diagnosed MM patients undergoing ASCT within 12 months from initial diagnosis. A single-center retrospective cohort study of newly diagnosed MM. Results: Patients were divided into 3 groups according to risk stratification: 1) low-risk, patients without del(17p13) nor t(14;16) or t(4;14) and ISS I/II;2) high-risk, patients with t(4;14), regardless of ISS stage; 3$)$ intermediate-risk, all remaining patients. The median PFS for the low-risk group was 18 months versus 13 months for the intermediate group $(p=0.047, H R=1.527,95 \% C I=1.006-2.316)$ versus 10 months for the high-risk group $(p<0.001, H R=2.656$, 95\%CI=1.572-4.490). Conclusion: An ISS/FISH-based
\end{abstract}

This article is freely accessible online.

Correspondence to: Ja Min Byun, MD, Department of Internal Medicine, Seoul Metropolitan Government Seoul National University Boramae Medical Center, Seoul, 07061 Republic of Korea. Tel: +82 28703238, Fax: +82 28310714, e-mail: jaminbyun@naver.com

Key Words: Multiple myeloma, autologous stem cell transplantation, prognostication, risk stratification. prognostication strategy was developed that can predict PFS for Asian MM patients undergoing ASCT.

Based on several randomized trials comparing ASCT to conventional chemotherapy, autologous stem cell transplantation (ASCT) preceding high dose therapy (HDT) is an established standard approach for frontline therapy in eligible multiple myeloma (MM) patients $(1,2)$. Even in the novel agent era, ASCT remains an integral part of treating younger patients with newly diagnosed MM (3-5). In fact, with the advent of new generation of proteasome inhibitors and immunomodulatory drugs (IMiDs), the role of ASCT is being augmented as means of solidifying the superior response and progression-free survival (PFS) of these drugs. As such, the number of patients undergoing ASCT is expected to increase, which in turn necessitates development of risk stratification methods to identify those who can benefit the most from ASCT.

Meanwhile, MM is a clonal plasma cell disorder with recurrent translocations at the immunoglobulin heavy chain $(\mathrm{IgH})$ locus on chromosome 14q32, deletions of chromosome 13 , and dysregulated expression of cyclin D genes $(6,7)$. These genetic aberrations, detected by fluorescent in situ hybridization (FISH), have emerged as major prognostic factors in recent years, leading to their incorporation into a risk stratification scheme and establishment of Revised International Staging System (R-ISS) (8). Using geneticbased risk stratification, previous studies have reported that there is a subpopulation of newly diagnosed MM patients who do not benefit from ASCT $(9,10)$. Unfortunately, Asian patients are under-represented in these studies despite being epidemiologically and cytogenetically different (11). Recognizing the lack of adaptive risk stratification methods 
Table I. Baseline characteristics of all 161 enrolled patients.

\begin{tabular}{|c|c|}
\hline Characteristics & $\mathrm{n}(\%)$ \\
\hline \multicolumn{2}{|l|}{ Age (years [range]) } \\
\hline Median & $58(18-69)$ \\
\hline \multicolumn{2}{|l|}{ Gender } \\
\hline Male & $81(50.3)$ \\
\hline \multicolumn{2}{|l|}{ Performance status } \\
\hline ECOG $0-1 / 2 / 3$ & $116(72.1) / 38(23.6) / 5(3.1)$ \\
\hline Missing & $2(1.2)$ \\
\hline \multicolumn{2}{|l|}{ Ig type } \\
\hline IgG/A/Others & $71(44.1) / 31(19.3) / 57(35.4)$ \\
\hline Light chain & $2(1.2)$ \\
\hline \multicolumn{2}{|l|}{ Light chain } \\
\hline Kappa/Lambda & $89(55.3) / 70(43.5)$ \\
\hline Missing & $2(1.2)$ \\
\hline \multicolumn{2}{|l|}{ ISS } \\
\hline I/II/III & $54(33.5) / 61(37.9) / 46(28.6)$ \\
\hline \multicolumn{2}{|l|}{ R-ISS } \\
\hline $\mathrm{I} / \mathrm{II} / \mathrm{III}$ & $48(29.8) / 52(32.3) / 61(37.9)$ \\
\hline \multicolumn{2}{|c|}{ Bone involvement at $\mathrm{MM}$ diagnosis } \\
\hline Involvement & $115(71.4)$ \\
\hline \multicolumn{2}{|l|}{ Azotemia at MM diagnosis } \\
\hline Creatinine $>2 \mathrm{mg} / \mathrm{dl}$ & $43(26.7)$ \\
\hline \multicolumn{2}{|l|}{ Laboratory results (mean $[ \pm \mathrm{SD}]$ ) } \\
\hline Serum M protein $(\mathrm{g} / \mathrm{dl})$ & $3.6(9.0)$ \\
\hline beta2-MG (mg/l) & $6.2(7.8)$ \\
\hline Hemoglobin (g/dl) & $10.1(2.3)$ \\
\hline Platelets $\left(10^{9} / 1\right)$ & $202.6(87.0)$ \\
\hline Calcium (mg/dl) & $9.5(1.4)$ \\
\hline Creatinine $(\mathrm{mg} / \mathrm{dl})$ & $1.5(1.8)$ \\
\hline Albumin $(\mathrm{mg} / \mathrm{dl})$ & $3.7(0.9)$ \\
\hline LDH (IU/L) & 196.7 (109.9) \\
\hline Bone marrow plasma cell $(\%)$ & $35.6(25.9)$ \\
\hline \multicolumn{2}{|c|}{ FISH abnormalities (positive/tested [\%]) } \\
\hline $\operatorname{del}(17 \mathrm{p} 13)$ & $7 / 97(7.2)$ \\
\hline $\operatorname{del}(13 q 14)$ & $58 / 156(37.2)$ \\
\hline $\mathrm{t}(14 ; 16)$ & $10 / 91(11.0)$ \\
\hline $\mathrm{t}(4 ; 14)$ & $25 / 88(28.4)$ \\
\hline$+1 \mathrm{q} 21$ & $61 / 153(39.9)$ \\
\hline $\operatorname{del}(9 \mathrm{p} 21)$ & $6 / 147(4.1)$ \\
\hline
\end{tabular}

ECOG: Eastern Cooperative Oncology Group; ISS: International Staging System; R-ISS: Revised International Staging System; MM: multiple myeloma; SD: standard deviation; MG: microglobulin; LDH: lactate dehydrogenase; FISH: fluorescence in situ hybridization.

specific to the Asian population undergoing ASCT, this study was conducted to evaluate the prognostic impact of genetic abnormalities, detected by FISH, on survival outcomes in combination with ISS classification.

\section{Patients and Methods}

Study design and subjects. This was a single-center retrospective longitudinal cohort study of newly diagnosed multiple myeloma patients undergoing ASCT within 12 months from initial diagnosis. Adult patients, defined as 18 years old or older were included, while cases with smoldering myeloma, monoclonal gammopathy of
Table II. Autologous stem cell transplantation.

\begin{tabular}{lc}
\hline Characteristics & $\mathrm{n}(\%)$ \\
\hline Induction regimen & \\
Thalidomide containing & $81(50.3)$ \\
Bortezomib containing & $22(13.7)$ \\
Lenalidomide containing & 0 \\
Others & $58(36.0)$ \\
Time from diagnosis to ASCT & \\
Median (months, range) & $6(3-12)$ \\
Pre-ASCT state & \\
CR & $19(11.8)$ \\
VGPR & $38(23.6)$ \\
PR & $44(47.8)$ \\
SD or worse & $27(16.8)$ \\
Response to ASCT & \\
CR & $78(48.4)$ \\
VGPR & $14(8.7)$ \\
PR & $26(16.1)$ \\
SD & $37(23.0)$ \\
Progression/Death/Loss to FU & $6(3.7)$ \\
Relapse after ASCT & $120(74.5)$ \\
Maintenance & \\
Total & $47(29.2)$ \\
Thalidomide-based & 24 \\
Bortezomib-based & 7 \\
Steroids & 14 \\
Ixazomib & 3 \\
Transplantation related mortality & $2(1.2)$ \\
\hline
\end{tabular}

ASCT: Autologous stem cell transplantation; CR: complete response; VGPR: very good partial response; PR: partial response; SD: stable disease; FU: follow-up.

unknown significance, solitary plasmacytoma and plasmablastic lymphoma were excluded. Patients who were not diagnosed at our center (i.e. referred patients), or who were part of clinical trials were also excluded. During the period between January 2005 and June 2015, 570 patients were initially identified and after excluding 317 for incomplete set of data and 92 for undergoing ASCT 12 months past diagnosis, a total of 161 patients with a complete set of molecular information were analyzed for their demographics, laboratory and clinical data. This study was conducted according to the Declaration of Helsinki and was approved by the institutional review board of Seoul National University Hospital (IRB No. H-1602-033-739).

Fluorescent in situ hybridization (FISH). FISH study was performed on bone marrow cells at diagnosis. Since there are no standard MM FISH probes used in Korea, 6 commercially available FISH probe sets were used. These included TP53 SpectrumOrange probe; D13S25 (13q14.3) SpectrumOrange probe; IgH/MAF dual color, dual fusion translocation probe; IgH/FGFR 3 dual color, dual fusion translocation probe; $1 \mathrm{q} 21 / 8 \mathrm{p} 21$ dual color probe; and CDKN2A (9p21, p16) SpectrumOrange/CEP9 SpectrumGreen probe (Abbott Diagnostics, Abbott Park, IL, USA). Positive signal was defined as an abnormal signal pattern detected in at least 2 metaphases.

Treatment. Since Korea has a public medical insurance system that is mandatory and covers approximately $98 \%$ of the overall Korean 

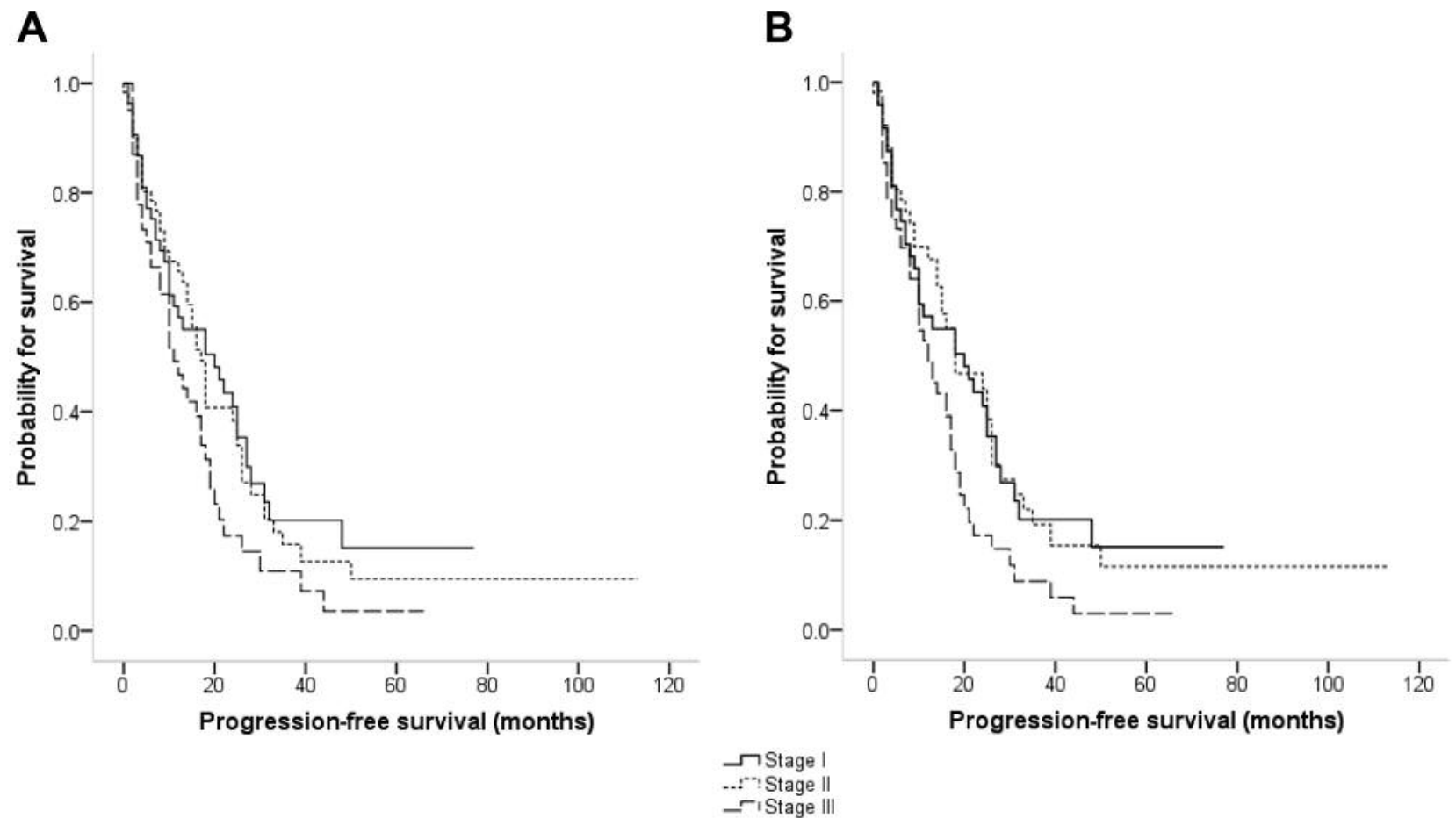

Figure 1. Impact of ISS and R-ISS on progression-free survival (PFS). (A) PFS according to International Staging System (ISS). (B) PFS according to Revised International Staging System (R-ISS).

population, the first line treatment algorithm was somewhat uniform throughout the cohort according to insurance regulations.

Peripheral blood stem cell collection was performed with granulocyte colony stimulating factor (G-CSF) alone. Stem cells were collected using mesenchymal cells and blood cell separator. The minimal number of collected CD34+ cells was $4 \times 10^{6} / \mathrm{kg}$. In selected cases, including those who failed adequate mobilization with G-CSF or less than optimal disease control with the initial therapy, chemotherapy-based mobilization using high-dose cyclophosphamide $\left(2-4 \mathrm{~g} / \mathrm{m}^{2}\right)$ was used. All patients were conditioned with the melphalan $200 \mathrm{mg} / \mathrm{m}^{2}$ protocol (melphalan $100 \mathrm{mg} / \mathrm{m}^{2}$ for 2 days), and 24-hours after conditioning the stem cells were re-infused. From the second day of re-infusion, G-CSF support was given to all patients until the absolute neutrophil count was greater than $0.5 \times 10^{9} / \mathrm{L}$ for 3 consecutive days. All patients underwent hematopoietic reconstruction. Since maintenance treatment is not covered by insurance, it was left to attending physicians to discuss the option with patients. Overall, 46 patients $(28.6 \%)$ received either thalidomide or bortezomib as maintenance.

Statistical analysis. PFS curves were estimated using the KaplanMeier method. If patients survived and death or progression did not occur, survival was censored at the date of the last follow-up when no death or progression was confirmed, and data available up to December 2016 were used. Univariate and multivariate proportional hazards regression models were used to identify independent risk factors of survival by Cox proportional hazards models. Predictors achieving a $p$-value below 0.05 in univariate analysis were sequentially preceded to multivariate analysis. Differences between groups were assessed using a Student's $t$-test or one-way analysis of variance for continuous variables, and Pearson chi-square test for categorical variables, as appropriate. All data were analyzed using the Statistical Package for the Social Sciences software $\left(\mathrm{IBM}^{\circledR}\right.$ SPSS $®$ Statistics, version 22.0). $p$-Values of $<0.05$ were considered statistically significant.

\section{Results}

Patient characteristics. The baseline characteristics of all 161 patients are presented in Table I. The median follow-up was 45 months from the time of diagnosis, with $86(53.4 \%)$ patients alive at last follow-up. The median age was 58 years (range $=18-69$ years) and $50.3 \%$ were male. According to ISS, 54 patients $(33.5 \%)$ were in stage I, $61(37.9 \%)$ in stage II and $46(28.6 \%)$ in stage III. According to R-ISS, 48 patients $(29.8 \%)$ were in stage I, $52(32.3 \%)$ in stage II and $61(37.9 \%)$ in stage III. The most commonly detected abnormality by FISH was +1q21 (39.9\%) followed by $\operatorname{del}(13 q 14)$, and $t(4 ; 14)$.

Autologous stem cell transplantation. Table II shows the parameters associated with ASCT. Induction regimen included thalidomide in 81 patients $(50.3 \%)$ and bortezomib in 22 patients $(13.7 \%)$. None received lenalidomide prior to ASCT. For those not exposed to novel agents, VAD 

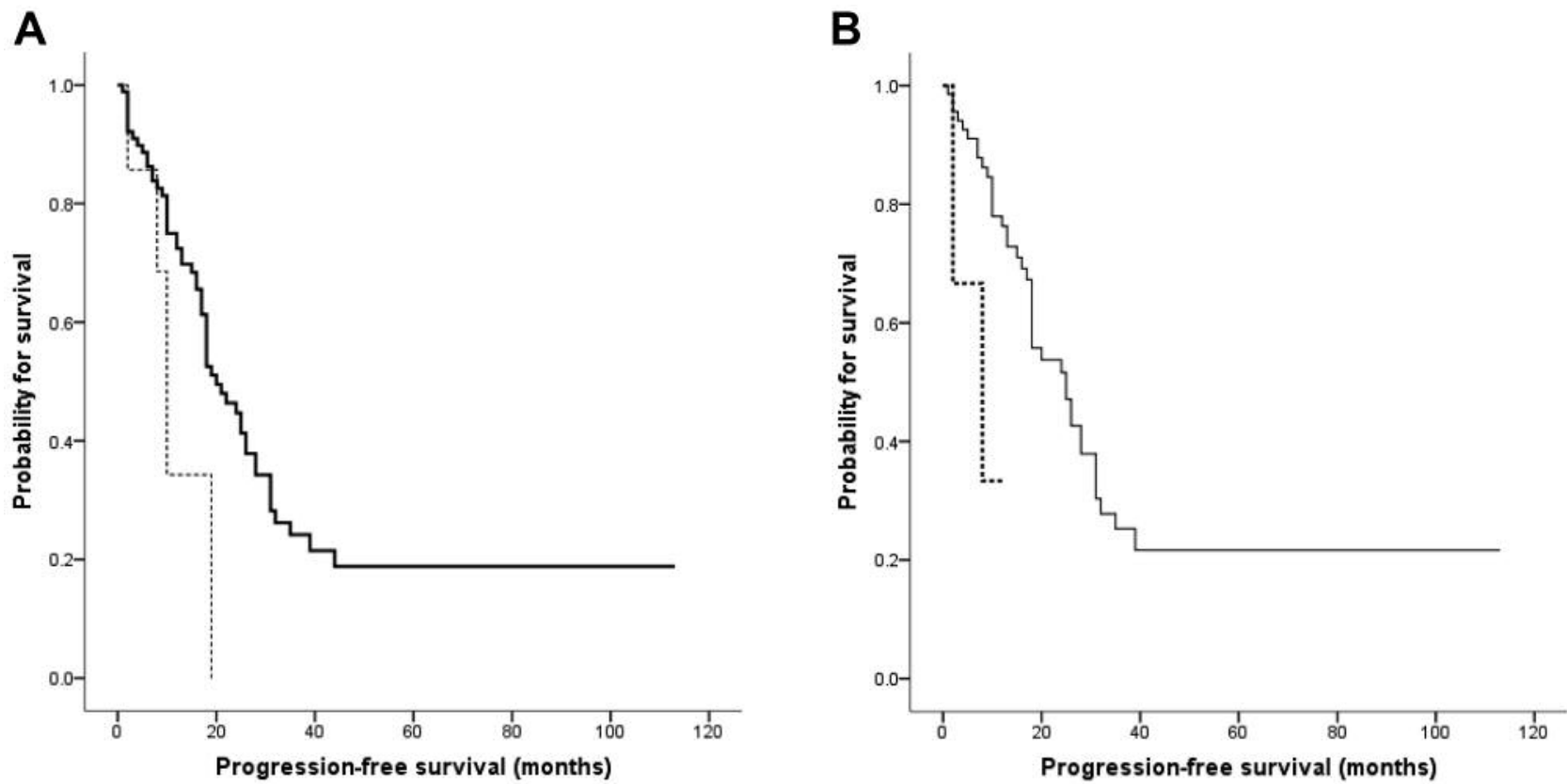

\begin{abstract}
(vincristine, doxorubicin, dexamethasone) was the most commonly used regimen $(n=50)$. At the time of ASCT, $35.4 \%$ of the patients had complete remission (CR) or very good partial response (VGPR). After ASCT, 57.1\% of the patients showed CR or VGPR. There were 52 patients who had PR or worse response to induction therapy 5 but subsequently achieved CR or VGPR with ASCT. There were 2 transplantation related mortalities (TRM): 1 patient deceased from liver failure and 1 patient from massive alveolar hemorrhage.
\end{abstract} Tdel(17p13) negative
$-\cdots$ del(17p13) positive

Impact of genetic aberration and ISS on clinical outcomes. For the entire cohort, the median PFS after ASCT was 16 months. The ISS score was a significant prognostic factor for PFS (Figure 1A). More specifically, patients with stage I disease had significantly better PFS compared to those with stage III disease $(p=0.037)$. Stage II patients showed trends towards a better PFS compared to stage III patients, but the difference did not reach statistical significance $(p=0.078)$. There was no statistical difference between stage I and stage II $(p=0.34)$. Similar patterns were observed for the R-ISS score (Figure 1B).

The presence of del(17p13) was associated with worse PFS overall ( $p=0.030$, median PFS 20 months for negative vs. 10 months for positive patients, respectively) (Figure 2A). These patients were further stratified by ISS classification. Among stage I and II patients, the presence of $\operatorname{del}(17 \mathrm{p} 13)$ was associated with worse PFS $(p=0.035$, Figure 2B) whereas for stage III patients, the presence of $\operatorname{del}(17 \mathrm{p} 13)$ did not have an impact on survival (Figure 2C).

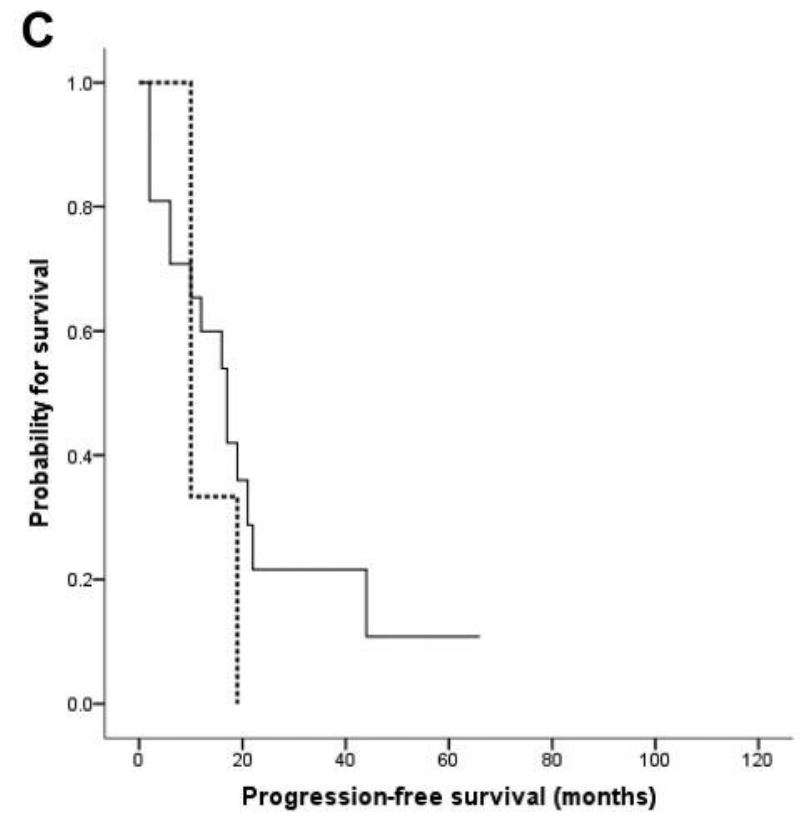

Figure 2. Impact of del(17p13) on progression free survival (PFS). (A) PFS of del(17p13) patients compared to those without. (B) Impact of del(17p13) on PFS in ISS stage I/II patients. (C) Impact of del(17p13) on PFS in ISS stage III patients.

The presence of $\mathrm{t}(14 ; 16)$ was associated with worse PFS ( $p=0.003$, median PFS 18 months for negative $v s .10$ months for positive patients, respectively) (Figure 3A). When further stratified by ISS classification, the presence of $\mathrm{t}(14 ; 16)$ was 


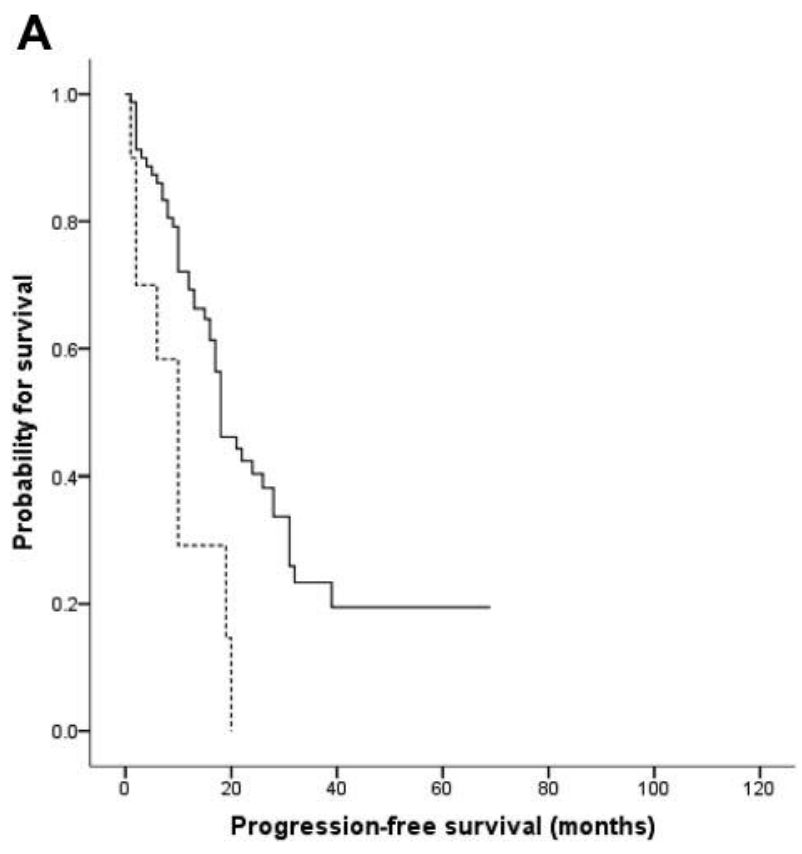

associated with worse PFS ( $p=0.031$, Figure 3B) among stage I and II patients. The presence of $\mathrm{t}(14 ; 16)$ did not have a significant impact on PFS of stage III patients (Figure 3C).

The presence of $\mathrm{t}(4 ; 14)$ was also associated with poorer outcomes $(p<0.001$, median PFS 24 months for negative $v s$. 10 months for positive patients, respectively) (Figure 4A). When these patients were further stratified by ISS classification, the presence of $\mathrm{t}(4 ; 14)$ was predictive of worse PFS in all stages (Figure 4B, C).

The impact of other genetic aberrations is presented in Table III.

Combining ISS classification and FISH for prognostication scheme. Based on survival analyses (Figures 1-4) and multivariate analysis (Table IV), our patients were divided into 3 groups according to risk stratification: 1) low-risk, patients without del(17p13) nor $\mathrm{t}(14 ; 16)$ or $\mathrm{t}(4 ; 14)$ and ISS I/II; 2$)$ highrisk patients with $\mathrm{t}(4 ; 14)$, regardless of ISS stage; 3) intermediate-risk, all remaining patients. There were 94 patients $(58.4 \%)$ in the low-risk group, $42(26.1 \%)$ in the intermediaterisk group and $25(15.5 \%)$ in the high-risk group. The median PFS for the low-risk group was 18 months versus 13 months for intermediate-risk group $(p=0.047, \mathrm{HR}=1.527,95 \% \mathrm{CI}=$ 1.006-2.316) versus 10 months for high-risk group $(p<0.001$, $\mathrm{HR}=2.656,95 \% \mathrm{CI}=1.572-4.490$ ) (Table V, Figure 5).

\section{Discussion}

Our study indicated that for newly diagnosed Asian multiple myeloma patients undergoing ASCT, risk stratification using

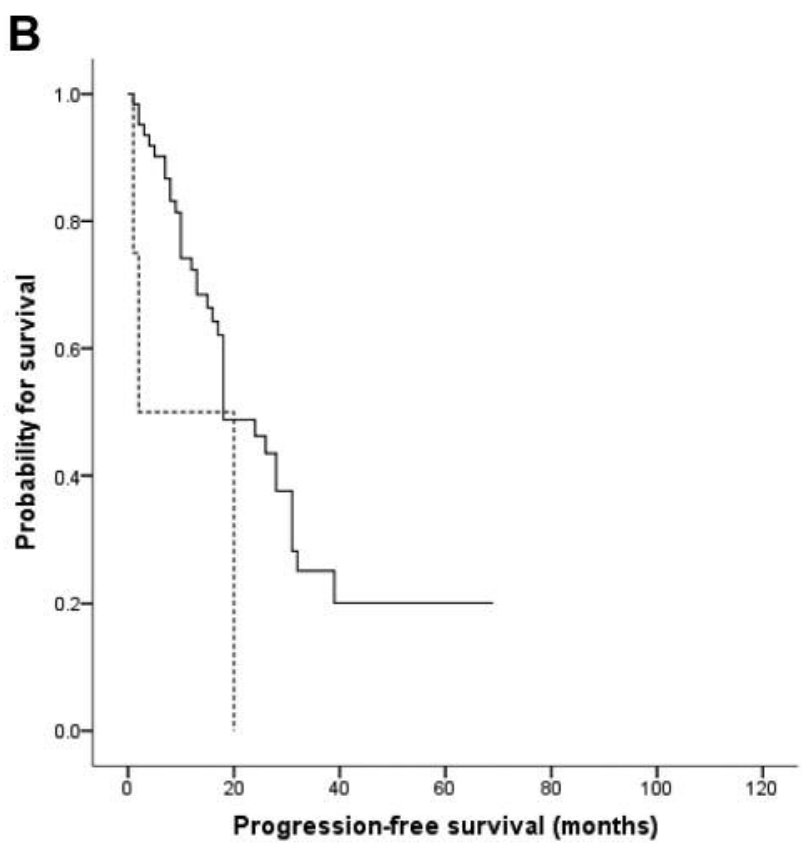

$\neg \mathrm{t}(14 ; 16)$ negative int(14;16) positive

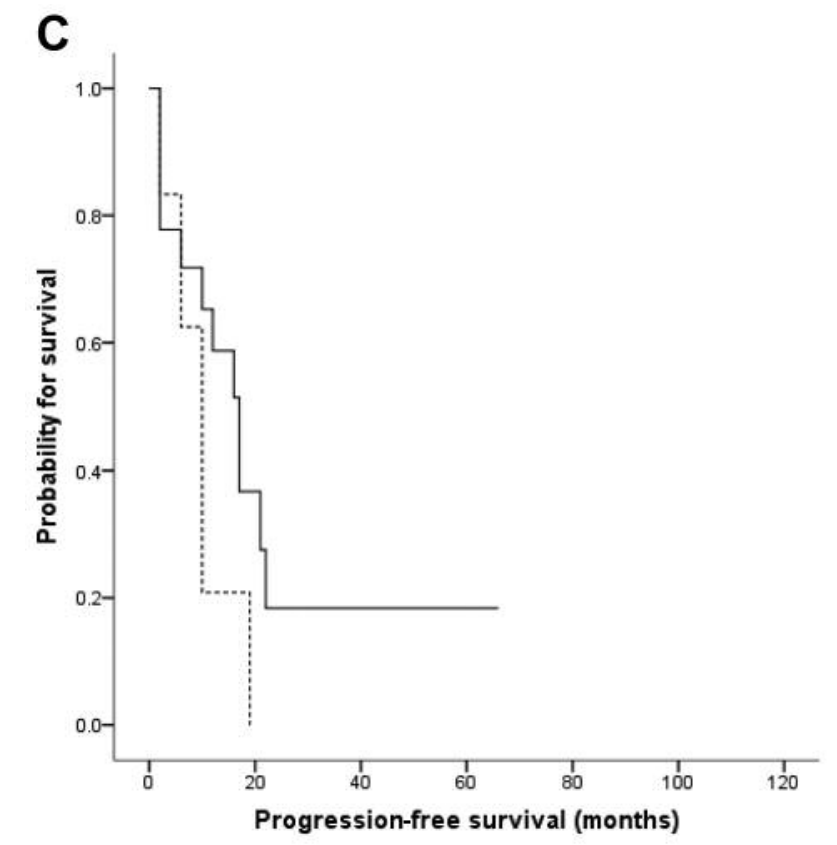

Figure 3. Impact of $t(14 ; 16)$ on progression free survival (PFS). (A) PFS of $t(14 ; 16)$ patients compared to those without. (B) Impact of $t(14 ; 16)$ on PFS in ISS stage I/II patients. (C) Impact of $t(14 ; 16)$ on PFS in ISS stage III patients.

R-ISS was somewhat unsatisfactory. As seen in Figure 1A, the survival for stage I patients did not differ from stage II patients ( $p=0.908$; median PFS 20 months vs. 18 months, 

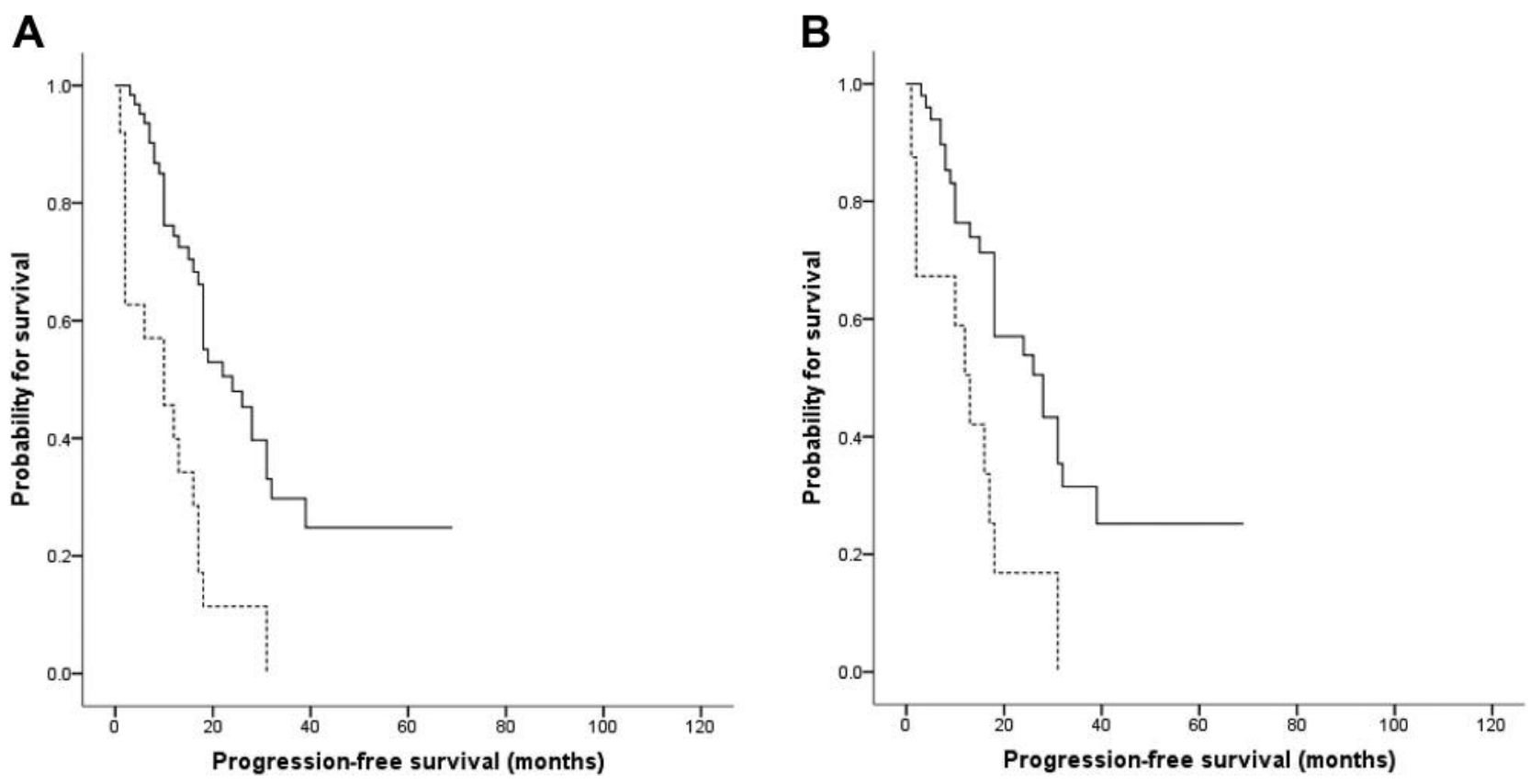

$-7 t(4 ; 14)$ negative
$-r+t(4 ; 14)$ postive

respectively). In recognizing the void of adoptive risk stratification unique to Asian MM patients, who are clinically and genetically different from Caucasian patients, this study was carried out to devise a prognostication scheme for Asian patients. Based on our analyses, ISS classification was combined with information on $\operatorname{del}(17 \mathrm{p} 13), \mathrm{t}(14 ; 16)$, and $\mathrm{t}(4 ; 14)$ to identify those who would benefit the most from ASCT. Using this scheme, the patients were categorized into 3 risk groups: low-risk group defined as ISS stage I/II patients without del(17p13) nor $\mathrm{t}(14 ; 16)$ nor $\mathrm{t}(4 ; 14)$; high-risk group defined as those with $\mathrm{t}(4 ; 14)$ regardless of ISS stage; and intermediate-risk group included all the rest. The high-risk group was associated with a significantly worse survival.

Through systematic evaluation of a homogeneous set of MM patients receiving fairly uniform induction and conduction regimens, ISS classification, $t(14 ; 16)$, $\operatorname{del}(17 \mathrm{p} 13)$ and $\mathrm{t}(4 ; 14)$ were identified as predictors of survival, as in previous reports $(8,10,12)$. Other factors, including maintenance therapy, and pre-ASCT state did not have significant impact on survival (Table IV). This study has important similarities and differences compared to previous reports. Most of the frequencies of FISH abnormalities were consistent with those described in larger series $(4,11-15)$ including del(17p13), del(13q14), t(4;14) and $+1 \mathrm{q} 21$. Notably, there was a larger proportion of patients with $\mathrm{t}(14 ; 16)$ in our cohort. The reported frequency of $\mathrm{t}(14 ; 16)$ varies from $1 \%$ to $3.2 \%$ depending on the study $(12,15)$ but $11 \%$ of our patients were found to carry this aberration. Since not much information is available on the

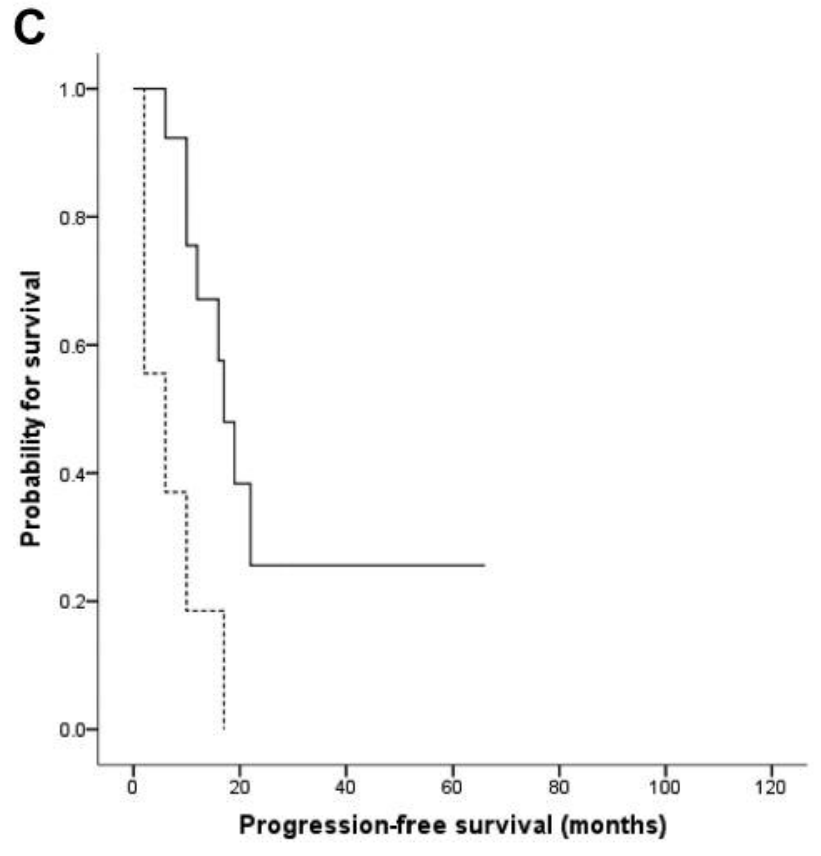

Figure 4. Impact of $t(4 ; 14)$ on progression-free survival (PFS). (A) PFS of $t(4 ; 14)$ patients compared to those without. (B) Impact of $t(4 ; 14)$ on PFS in ISS stage I/II patients. (C) Impact of $t(4 ; 14)$ on PFS in ISS stage III patients.

frequencies of FISH abnormalities from East Asian patients, it is not certain that this trait is indeed a unique finding. However, a recent large-scale study from the International 
Table III. Survival outcomes according to FISH at diagnosis.

\begin{tabular}{|c|c|c|}
\hline FISH & $\mathrm{PFS}^{1}$ & Log-rank $p$-Value \\
\hline \multicolumn{3}{|l|}{$\operatorname{del}(17 \mathrm{p} 13)$} \\
\hline Positive $(\mathrm{n}=7)$ & $10.0(15.2-24.8)$ & 0.030 \\
\hline Negative $(\mathrm{n}=90)$ & $20.0(7.8-12.2)$ & \\
\hline \multicolumn{3}{|l|}{ del (13q14) } \\
\hline Positive $(n=58)$ & $17.0(13.5-20.5)$ & 0.425 \\
\hline Negative $(n=98)$ & $15.0(10.4-19.6)$ & \\
\hline \multicolumn{3}{|l|}{$t(14 ; 16)$} \\
\hline Positive $(\mathrm{n}=10)$ & $10.0(5.5-14.5)$ & 0.003 \\
\hline Negative $(\mathrm{n}=81)$ & $18.0(14.0-22.0)$ & \\
\hline \multicolumn{3}{|l|}{$\mathrm{t}(4 ; 14)$} \\
\hline Positive $(n=25)$ & $10.0(2.4-17.6)$ & $<0.001$ \\
\hline Negative $(n=63)$ & $24.0(14.9-33.1)$ & \\
\hline \multicolumn{3}{|l|}{$+1 \mathrm{q} 21$} \\
\hline Positive $(n=61)$ & $12.0(6.8-17.2)$ & 0.050 \\
\hline Negative $(\mathrm{n}=92)$ & $18.0(13.9-22.1)$ & \\
\hline \multicolumn{3}{|l|}{$\operatorname{del}(9 \mathrm{p} 21)$} \\
\hline Positive $(n=6)$ & $13.0(2.3-23.7)$ & 0.735 \\
\hline Negative $(n=141)$ & $15.0(11.9-18.1)$ & \\
\hline
\end{tabular}

FISH: Fluorescence in situ hybridization; ISS: International Staging System; PFS: progression free survival. ${ }^{1}$ Values presented as median (months, 95\% confidence intervals of median).

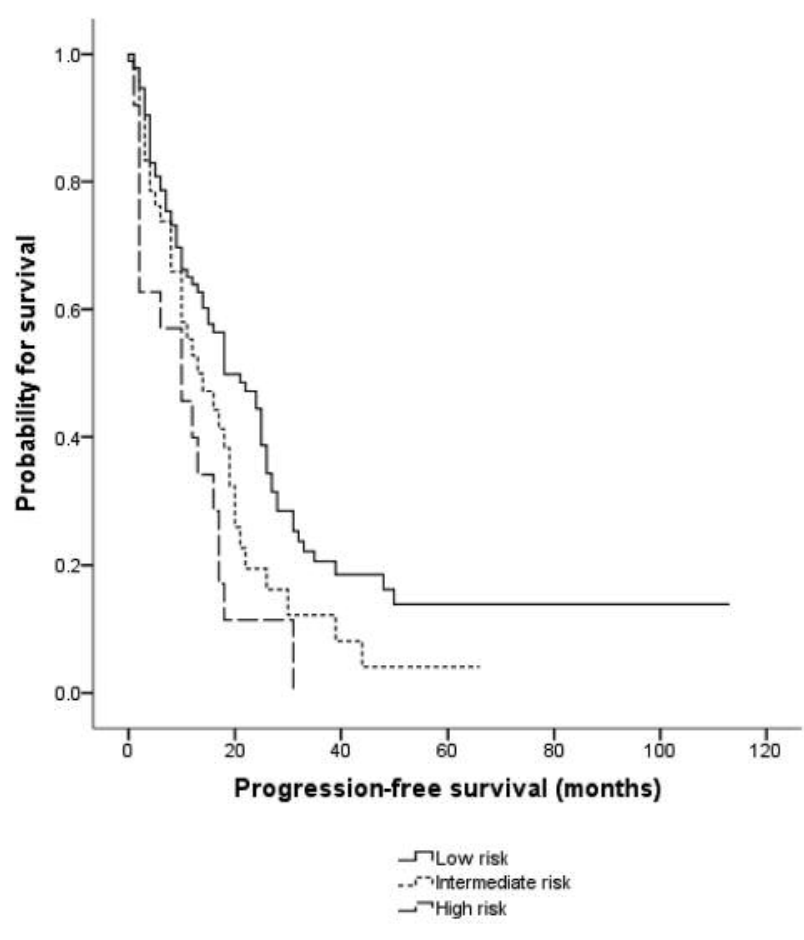

Figure 5. Combining information on genetic aberrations with International Staging System (ISS) classification for risk stratification.

Table IV. Univariate and multivariate analysis for progression free survival.

\begin{tabular}{|c|c|c|c|c|}
\hline \multirow[t]{2}{*}{ Parameters } & \multicolumn{2}{|c|}{ Univariate } & \multicolumn{2}{|c|}{ Multivariate } \\
\hline & HR $(95 \% \mathrm{CI})$ & $p$-Value & HR $(95 \% \mathrm{CI})$ & $p$-Value \\
\hline \multicolumn{5}{|l|}{ ISS } \\
\hline Stage I & ref & ref & ref & ref \\
\hline Stage II & $1.090(0.705-1.684)$ & 0.699 & $0.853(0.418-1.741)$ & 0.663 \\
\hline Stage III & $1.600(1.015-2.523)$ & 0.043 & $1.290(0.578-2.880)$ & 0.534 \\
\hline del(17p13) (Positive vs. Negative) & $2.667(1.038-6.854)$ & 0.042 & $1.659(0.542-5.073)$ & 0.375 \\
\hline $\mathrm{t}(14 ; 16)$ (Positive $v s$. Negative) & $2.932(1.357-6.334)$ & 0.006 & $2.107(0.735-6.041)$ & 0.165 \\
\hline $\mathrm{t}(4 ; 14)$ (Positive $v s$. Negative) & $3.517(1.958-6.317)$ & $<0.001$ & $3.584(1.848-6.951)$ & $<0.001$ \\
\hline Maintenance (Yes $v s$. No) & $0.710(0.473-1.065)$ & 0.098 & NA & NA \\
\hline \multicolumn{5}{|l|}{ Pre-ASCT state } \\
\hline CR and VGPR & ref & ref & NA & NA \\
\hline PR & $1.259(0.837-1.895)$ & 0.269 & NA & NA \\
\hline SD or worse & $1.358(0.801-2.303)$ & 0.256 & NA & NA \\
\hline
\end{tabular}

HR: Hazard ratio; CI: confidence interval; R-ISS: Revised International Staging System; ref: reference; NA: not applicable; ISS: International Staging System; ASCT: autologous stem cell transplantation; CR: complete response; VGPR: very good partial response; PR: partial response; SD: stable disease.

Myeloma Foundation (11), which included countries like China, Hong Kong, Japan, Korea, Singapore, Taiwan and Thailand, reported that $4.4 \%$ of the study cohort carried $t(14 ; 16)$, suggesting a trend towards a higher frequency of $\mathrm{t}(14 ; 16)$ in Asians.
The presence of $\mathrm{t}(4 ; 14)$ was a strong prognostic factor for ASCT PFS in our cohort. Coincidentally, 2 patients who died from TRM also showed $t(4 ; 14)$. While the number of TRM cases is too small for further evaluation, this finding could indicate that patients with $t(4 ; 14)$ do not respond very well 
Table V. Prognostic impact of genetic aberrations in combination with ISS score on progression-free survival (Cox proportional hazards analysis).

\begin{tabular}{lcr}
\hline Parameters & \multicolumn{2}{c}{ PFS } \\
\cline { 2 - 3 } & HR $(95 \% \mathrm{CI})$ & $p$-Value \\
\hline Low-risk $^{1}$ & ref & \\
Intermediate-risk $^{2}$ & $1.527(1.006-2.316)$ & 0.047 \\
High-risk $^{3}$ & $2.656(1.572-4.490)$ & $<0.001$ \\
\hline
\end{tabular}

HR: Hazard ratio; CI: confidence interval; PFS: progression-free survival. ${ }^{1}$ Patients without $\operatorname{del}(17 \mathrm{p} 13)$ nor $\mathrm{t}(14 ; 16)$ nor $\mathrm{t}(4 ; 14)$ and ISS I/II; ${ }^{2}$ Patients with ISS III, or, patients with del(17p13) or t(14;16); ${ }^{3}$ Patients with $\mathrm{t}(4 ; 14)$, regardless of ISS stage.

to high-dose melphalan treatment. Also, among the 52 patients who had suboptimal response to induction treatment, but subsequently achieved CR or VGPR, the proportion of patients bearing $\mathrm{t}(4 ; 14)$ was smaller $(13 / 5 \%)$ compared to the total cohort $(28.4 \%)$. Other genetic aberrations in this subgroup showed similar distribution compared to the total cohort. It would be interesting to investigate if patients harboring $\mathrm{t}(4 ; 14)$ would benefit from novel agent induction, namely bortezomib, lenalidomide and carfilzomib, and if these agents can overcome the adverse prognosis of ASCT.

One of the pitfalls of our study is the lack of information on some chromosomal aberrations that are traditionally recognized to have prognostic value, including $\mathrm{t}(11 ; 14)$ and $\mathrm{t}(14 ; 20)$. This, however, ironically highlights the current circumstances where there is no standardized FISH panel specific to the Korean population, despite the steadily increasing number of MM patients in the country $(16,17)$. Collaborative efforts from different centers are necessary to define the molecular and cytogenetic characteristics of Korean MM patients, and develop adoptive risk stratification methods to reflect such information plus social and economic statuses. The small number of patients in each FISH group is also a limitation of this study. Although the total number of patients in our cohort itself is not small by any means, especially considering the fact that these were fairly homogeneously-treated patients from a single center, the absolute number of patients carrying a specific chromosomal aberration was small in some cases. Even so, since they delineated survival outcomes, our results are predicted to be consolidated with a larger population. All in all, our data add valuable knowledge to prognostic factors for MM and assist in selecting patients suitable for ASCT.

\section{Conclusion}

In conclusion, we developed an ISS/FISH-based prognostication strategy based on our findings, and showed that this stratification can predict PFS for Asian MM patients undergoing ASCT. For patients in the high-risk group, alternative, more innovative induction and consolidative treatment approaches should be offered.

\section{Conflicts of Interest}

The Authors have no conflicts of interest to disclose regarding this study.

\section{Authors' Contributions}

Conception and design: Ja Min Byun, Sung-Soo Yoon. Provision of study materials: Dong-Yeop Shin, Inho Kim, Sung-Soo Yoon, Yougil Koh. Collection and assembly of data: Ja Min Byun, Daeyoon Kim. Data analysis and interpretation: Ja Min Byun, Daeyoon Kim, Sung-Soo Yoon. Manuscript writing: all authors. Final approval of manuscript: all authors.

\section{Acknowledgements}

The abstract of this manuscript has been submitted to the International Myeloma Workshop 2017, held at New Delhi, India, March 1-4, 2017. This research was supported by a grant from the Korea Health Technology R\&D Project through the Korea Health Industry Development Institute (KHIDI), funded by the Ministry of Health \& Welfare, Republic of Korea (grant number: HC15C3397).

\section{References}

1 Child JA, Morgan GJ, Davies FE, Owen RG, Bell SE, Hawkins K, Brown J, Drayson MT and Selby PJ: Medical Research Council Adult Leukaemia Working Party: High-dose chemotherapy with hematopoietic stem-cell rescue for multiple myeloma. N Engl J Med 348(19): 1875-1883, 2003. PMID: 12736280, DOI: 10.1056/NEJMoa022340

2 Attal M, Harousseau JL, Stoppa AM, Sotto JJ, Fuzibet JG, Rossi JF, Casassus P, Maisonneuve H, Facon T, Ifrah N, Payen C and Bataille R: A prospective, randomized trial of autologous bone marrow transplantation and chemotherapy in multiple myeloma. Intergroupe Francais du Myelome. N Engl J Med 335(2): 91-97, 1996. PMID: 8649495, DOI: 10.1056/NEJM199607113350204

3 Moreau P and Attal M: All transplantation-eligible patients with myeloma should receive ASCT in first response. Hematology Am Soc Hematol Educ Program 2014(1): 250-254, 2014. PMID: 25696863, DOI: 10.1182/asheducation-2014.1.250

4 Kaufman GP, Gertz MA, Dispenzieri A, Lacy MQ, Buadi FK, Dingli D, Hayman SR, Kapoor P, Lust JA, Russell S, Go RS, Hwa YL, Kyle RA, Rajkumar SV and Kumar SK: Impact of cytogenetic classification on outcomes following early high-dose therapy in multiple myeloma. Leukemia 30(3): 633-639, 2016. PMID: 25696863, DOI: 10.1182/asheducation-2014.1.250

5 Richardson PG, Laubach JP, Munshi NC and Anderson KC: Early or delayed transplantation for multiple myeloma in the era of novel therapy: does one size fit all? Hematology Am Soc Hematol Educ Program 2014(1): 255-261, 2004. PMID: 25696864, DOI: 10.1182/asheducation-2014.1.255 
6 Avet-Loiseau H, Brigaudeau C, Morineau N, Talmant P, Laï JL, Daviet A, Li JY, Praloran V, Rapp MJ, Harousseau JL, Facon T and Bataille R: High incidence of cryptic translocations involving the Ig heavy chain gene in multiple myeloma, as shown by fluorescence in situ hybridization. Genes Chromosomes Cancer 24(1): 9-15, 1999. PMID: 9892103

7 Sahota S, Hamblin T, Oscier DG, and Stevenson FK: Assessment of the role of clonogenic B lymphocytes in the pathogenesis of multiple myeloma. Leukemia 8(8): 1285-1289, 1994. PMID: 8057663

8 Palumbo A, Avet-Loiseau H, Oliva S, Lokhorst HM, Goldschmidt H, Rosinol L, Richardson P, Caltagirone S, Lahuerta JJ, Facon T, Bringhen S, Gay F, Attal M, Passera R, Spencer A, Offidani M, Kumar S, Musto P, Lonial S, Petrucci MT, Orlowski RZ, Zamagni E, Morgan G, Dimopoulos MA, Durie BG, Anderson KC, Sonneveld P, San Miguel J, Cavo M, Rajkumar SV and Moreau P: Revised International Staging System for Multiple Myeloma: A Report From International Myeloma Working Group. J Clin Oncol 33(26): 2863-2869, 2015. PMID: 26240224, DOI: 10.1200/JCO.2015.61.2267

9 Chang H, Qi XY, Samiee S, Yi QL, Chen C, Trudel S, Mikhael J, Reece D, and Stewart AK: Genetic risk identifies multiple myeloma patients who do not benefit from autologous stem cell transplantation. Bone Marrow Transplant 36(9): 793-796, 2005. PMID: 16113669, DOI: 10.1038/sj.bmt.1705131

10 Moreau P, Cavo M, Sonneveld P, Rosinol L, Attal M, Pezzi A, Goldschmidt H, Lahuerta JJ, Marit G, Palumbo A, van der Holt B, Bladé J, Petrucci MT, Neben K, san Miguel J, Patriarca F, Lokhorst H, Zamagni E, Hulin C, Gutierrez N, Facon T, Caillot D, Benboubker L, Harousseau JL, Leleu X, Avet-Loiseau H and Mary JY: Combination of international scoring system 3, high lactate dehydrogenase, and $\mathrm{t}(4 ; 14)$ and/or del(17p) identifies patients with multiple myeloma (MM) treated with front-line autologous stem-cell transplantation at high risk of early MM progression-related death. J Clin Oncol 32(2): 2173-2180, 2014. PMID: 24888806, DOI: 10.1200/JCO.2013.53.0329

11 Kim K, Lee JH, Kim JS, Min CK, Yoon SS, Shimizu K, Chou T, Kosugi H, Suzuki K, Chen W, Hou J, Lu J, Huang XJ, Huang SY, Chng WJ, Tan D, Teoh G, Chim CS, Nawarawong W, Siritanaratkul $\mathrm{N}$ and Durie BG: Clinical profiles of multiple myeloma in Asia-An Asian Myeloma Network study. Am J Hematol 89(7): 751-756, 2014. PMID: 24723430, DOI: 10.1002/ajh.23731
12 Neben K, Jauch A, Bertsch U, Heiss C, Hielscher T, Seckinger A, Mors T, Müller NZ, Hillengass J, Raab MS, Ho AD, Hose D and Goldschmidt $\mathrm{H}$ : Combining information regarding chromosomal aberrations $\mathrm{t}(4 ; 14)$ and $\operatorname{del}(17 \mathrm{p} 13)$ with the International Staging System classification allows stratification of myeloma patients undergoing autologous stem cell transplantation. Haematologica 95(7): 1150-1157, 2010. PMID: 20220069, DOI: 10.3324/haematol.2009.016436

13 Fonseca R, Blood E, Rue M, Harrington D, Oken MM, Kyle RA, Dewald GW, Van Ness B, Van Wier SA, Henderson KJ, Bailey RJ and Greipp PR: Clinical and biologic implications of recurrent genomic aberrations in myeloma. Blood 101(11): 4569-4575, 2003. PMID: 12576322, DOI: 10.1182/blood-2002-10-3017

14 Ross FM, Avet-Loiseau H, Ameye G, Gutiérrez NC, Liebisch P, O'Connor S, Dalva K, Fabris S, Testi AM, Jarosova M, Hodkinson C, Collin A, Kerndrup G, Kuglik P, Ladon D, Bernasconi P, Maes B, Zemanova Z, Michalova K, Michau L, Neben K, Hermansen NE, Rack K, Rocci A, Protheroe R, Chiecchio L, Poirel HA, Sonneveld P, Nyegaard M and Johnsen HE; European Myeloma Network: Report from the European Myeloma Network on interphase FISH in multiple myeloma and related disorders. Haematologica 97(8): 1272-1277, 2012. PMID: 22371180, DOI: 10.3324/haematol.2011.056176

15 Jian Y, Chen X, Zhou H, Zhu W, Liu N, Geng C, and Chen W: Prognostic impact of cytogenetic abnormalities in multiple myeloma: A retrospective analysis of 229 patients. Medicine (Baltimore) 95(19): e3521, 2016. PMID: 27175647, DOI: 10.1097/MD.0000000000003521

16 Park HJ, Park EH, Jung KW, Kong HJ, Won YJ, Lee JY, Yoon JH, Park BK, Lee H, Eom HS and Park S: Statistics of hematologic malignancies in Korea: incidence, prevalence and survival rates from 1999 to 2008. Korean J Hematol 47(1): 2838, 2012. PMID: 22479275, DOI: 10.5045/kjh.2012.47.1.28

17 Jung KW, Won YJ, Kong HJ, Oh CM, Cho H, Lee DH and Lee KH: Cancer statistics in Korea: incidence, mortality, survival, and prevalence in 2012. Cancer Res Treat 47(2): 127-141, 2015. PMID: 25761484, DOI: 10.4143/crt.2015.060

Received December 19, 2018 Revised January 9, 2019 Accepted January 14, 2019 